\title{
Numerical Simulation of the Impact ofIce Accumulation on a Composite Wind Turbine Blades located in a Cold Climate
}

\author{
O. Lagdani ${ }^{1 *}$, M. Tarfaoui ${ }^{2}$, M. Nachtane ${ }^{3}$, M. Trihi ${ }^{1}$ and H. Laaouidi ${ }^{1}$ \\ ${ }^{1}$ Laboratory for Renewable Energy and Dynamic Systems, FSAC - UH2C, Morocco \\ ${ }^{2}$ ENSTA Bretagne, IRDL UMR CNRS 6027, F-29200 Brest, France \\ ${ }^{3}$ University of Bordeaux, CNRS, Arts et Metiers Institute of Technology, Bordeaux INP, INRAE, I2M Bordeaux, F-33400 \\ Talence, France \\ Oumnialagdani@gmail.com,mostapha.tarfaoui@ensta-bretagne.fr
}

\begin{abstract}
Keywords: Cold climate, Composite wind turbine blade, Ice Accretion,Numerical analysis, Hashin criterion, Finite element analysis.

Abstract: $\quad$ The blades of wind turbines placed in cold climate regions are exposed to the risk of icing phenomena which impact their lifetimes. This paper proposes a numerical model to simulate $50 \mathrm{~mm}$ ice thickness localized on the tip side of a horizontal wind turbine blade,and to study its mechanical behavior. The wind turbine blade wasmodeled with the finite element method (FEM)in ABAQUS software taking into account aerodynamic, centrifugal and inertial loads under the conditions of service of the blade.Numerical tests haveevaluated the behavior of different composite materials and compared with each other. Damage mode based on the Hashin criteria was defined. Carbon fibers were considered to be the most rigid material which results in thinner, stiffer and lighter blades.
\end{abstract}

\section{INTRODUCTION}

Offshore wind energy is among the most advanced and modern technologies currently available to provide clean energy, due to the high average wind speeds that regularly blow over the oceans[1]. Cold regions are considered as the best areas for wind energy, which is therefore a dynamic and growing sector.However, one of the problems encountered in these zones is the accumulation of ice on the surface of wind turbines. The wind energy loss depends mainly on the quantity of ice accreted on the blades[2].The icing processresultsa considerabledegradation of energydue to performance deteriorationcaused byexcessive vibration problems of the rotor.It is also necessary to note the severedangers caused by ice projection from the bladeproducing unpleasant noise [3].

Composite materials such as Carbon or Glass fibers are used as alternative materials to steel because of their significant potential advantages in offshore applicationsand their attractive properties [4].The formation of ice on severalparts of the wind turbine using these materials will affect their mechanical properties.
In the present paper, a numerical analysis has been performed to study the mechanical behavior and the influence of ice formation on offshore wind turbine blades. The analysis is presented using ABAQUS software based on the Finite Element Method (FEM) taking into account different aerodynamic loads and using several materials.

2

STRUCTURALPERFORMANC ES ANALYSIS

\subsection{Structural configuration of the blade}

The system adopted for this study is composed of a rigid three-bladed offshore wind turbine. The blade is manufactured to produce $5 \mathrm{MW}$ of a maximumpower using NACA 4412 profile with well-known aerodynamic characteristics[5]-[6].

The parameters of the model used are summarizedin Table 1. 
Table 1: Specifications of the wind turbine blade

\begin{tabular}{|c|c|}
\hline Airfoil & NACA 4412 \\
\hline Length of the blade (m) & 48 \\
\hline Number of blades & 3 \\
\hline Maximum chord (mm) & 3932 \\
\hline Position twists maximum (mm) & R9000 \\
\hline Fluid speed upstream of the blade (m/s) & 25 \\
\hline Angular velocity (rpm) & 15.7 \\
\hline
\end{tabular}

Rotor blade consists of severalparts combined together to form the aerofoil shape, in order to provide a greater number of possible combinationsof the materials employed as required, Figure 1[7]-[8].

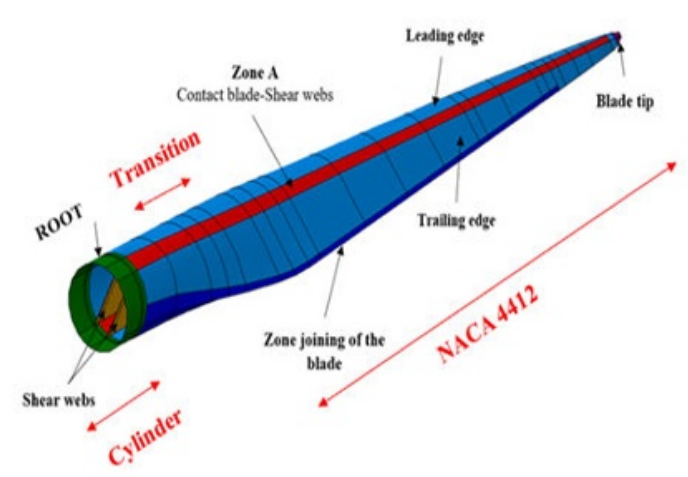

Figure 1: Division of the blade structure

\subsection{Mechanical properties description}

The majority of the wind turbines blades are manufactured by using composite materials because of their interesting properties and excellent mass/durability relations[9]-[10]. Carbon and Glass fibers have been chosen to evaluate the behavior of the blade. Their characteristic properties are summarized in Table 2.

Table2: Mechanical properties of the materials employed in the analysis of the wind turbine blade

\begin{tabular}{|c|c|c|c|}
\hline & $\begin{array}{c}\text { Material } \\
\text { Properties }\end{array}$ & $\begin{array}{l}\text { Carbon- } \\
\text { epoxy [11] }\end{array}$ & $\begin{array}{c}\text { Glass- } \\
\text { polyester [12] }\end{array}$ \\
\hline & $\rho\left(\mathrm{kg} / \mathrm{m}^{3}\right)$ & 1600 & 1960 \\
\hline \multirow{6}{*}{$\begin{array}{c}\text { Engin } \\
\text { eerin } \\
g \\
g \\
\text { const } \\
\text { antc }\end{array}$} & $\mathrm{E}_{1}(\mathrm{GPa})$ & 147 & 48.16 \\
\hline & $\begin{array}{c}\mathrm{E}_{2}(\mathrm{GPa})= \\
\mathrm{E}_{3}(\mathrm{GPa})\end{array}$ & 10.3 & 11.210 \\
\hline & $\mathrm{Nu}_{12}=\mathrm{Nu}_{13}$ & 0.27 & 0.270 \\
\hline & $\mathrm{Nu}_{23}$ & 0.54 & 0.096 \\
\hline & $\begin{array}{c}\mathrm{G}_{12}(\mathrm{GPa})= \\
\mathrm{G}_{13}(\mathrm{GPa})\end{array}$ & 7 & 4.420 \\
\hline & $\mathrm{G}_{23}(\mathrm{GPa})$ & 3.7 & 9 \\
\hline \multirow[b]{2}{*}{ Stren } & $\mathrm{X}_{\mathrm{t}}(\mathrm{MPa})$ & 2041 & 1021 \\
\hline & $\mathrm{X}_{\mathrm{c}}(\mathrm{MPa})$ & 1784 & 978 \\
\hline
\end{tabular}

gth

prope

rties

\begin{tabular}{|c|c|c|c|}
\cline { 2 - 4 } & $\mathrm{Y}_{\mathrm{t}}(\mathrm{MPa})$ & 58.7 & 29.5 \\
\cline { 2 - 4 } & $\mathrm{Y}_{\mathrm{c}}(\mathrm{MPa})$ & 24.78 & 171.8 \\
\cline { 2 - 4 } & $\mathrm{S}_{\mathrm{t}}=\mathrm{S}_{\mathrm{c}}(\mathrm{MPa})$ & 65.6 & 35.3 \\
\hline
\end{tabular}

\section{HASHIN'S THEORY}

Hashin's model is among the most popular criteria and widely used in composite structure applications due to its simplicity of design and ease of use[13].The Hashin type failure criterionhas been employed to predict and detect damage in composite structures.It consists of two failure mechanisms, one associated with fiber failure and the other with matrix failure, differentiating between tension and compression[14]-[15].

The four distinct modes of damageare represented as follows:

Fiber tension(HSNFTCRT), $\widehat{\sigma}_{11} \geq \mathbf{0}$ :

$$
\left(\frac{\widehat{\sigma}_{11}}{X_{T}}\right)^{2}+\alpha \times\left(\frac{\widehat{\sigma}_{12}}{S_{L T}}\right)^{2}=f_{1}
$$

Fiber compression(HSNFCCRT), $\widehat{\sigma}_{11}<0$ :

$$
\left(\frac{\widehat{\sigma}_{11}}{X_{T}}\right)^{2}+\alpha \times\left(\frac{\widehat{\sigma}_{12}}{S_{L T}}\right)^{2}=f_{1}
$$

Matrix tension (HSNMTCRT), $\widehat{\sigma}_{22} \geq 0$ :

$$
\left(\frac{\widehat{\sigma}_{11}}{X_{T}}\right)^{2}+\alpha \times\left(\frac{\widehat{\sigma}_{12}}{S_{L T}}\right)^{2}=f_{1}
$$

Matrix compression (HSNMCCRT), $\widehat{\sigma}_{22}<0$ :

$$
\left(\frac{\widehat{\sigma}_{11}}{X_{T}}\right)^{2}+\alpha \times\left(\frac{\widehat{\sigma}_{12}}{S_{L T}}\right)^{2}=f_{1}
$$

\section{NUMERICAL ANALYSIS}

\subsection{Boundary Conditions}

Figure 2 illustrates the boundary condition assigned to the blade using "Encastre" type applied at the $\operatorname{root}[16]$.

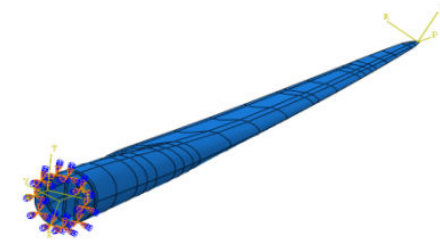

Figure 2: Encastre boundary condition

\subsection{Loads}


Wind turbines are subject to various loads applied to their entirestructure. They are defined as aerodynamic loads that aregenerated by a rotor blade, and operating on it are greatly variable in intensity because of the stochastic character of the wind field. Inertia and gravitational loadsare also taken into account in this study[17].

The three loads were then simultaneously applied using the ABAQUS software on a horizontal blade Figure 3, containing ice at the end of the structureas shown in the Figure 4. Table 3 provides some ice layer informationused in this study.

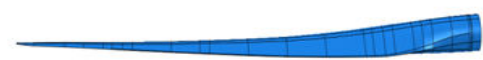

7

Figure 3: Position of the blade

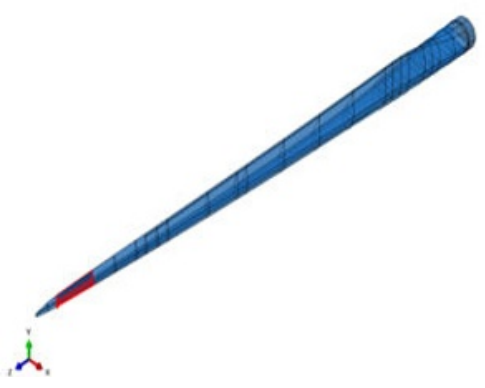

Figure 4: Iced wind turbine blade

Table 3: Ice layer information

\begin{tabular}{cccc}
\hline $\begin{array}{c}\text { Length of } \\
\text { ice cover } \\
(\mathbf{m})\end{array}$ & $\begin{array}{c}\text { Distance } \\
\text { from rotor } \\
(\mathbf{m})\end{array}$ & $\begin{array}{c}\text { Thickness } \\
\text { of ice } \\
(\mathbf{m m})\end{array}$ & $\begin{array}{c}\text { Mass of } \\
\text { ice (kg) }\end{array}$ \\
\hline 3.21 & 43.031 & 50 & 0.303 \\
\hline
\end{tabular}

\section{RESULTS AND ANALYSIS}

After defining and identifying the loads, our first objective is to analyze the behavior of the blade using both Carbon and Glass fibers, and then discover the effect of the hybrid Carbon-Glass located at section $\mathrm{C}$ of a Carbon blade, as presented before in Figure 1.

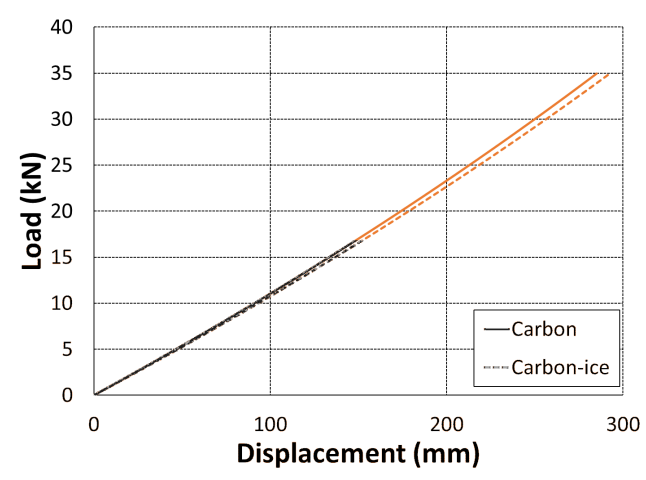

(a) Carbon

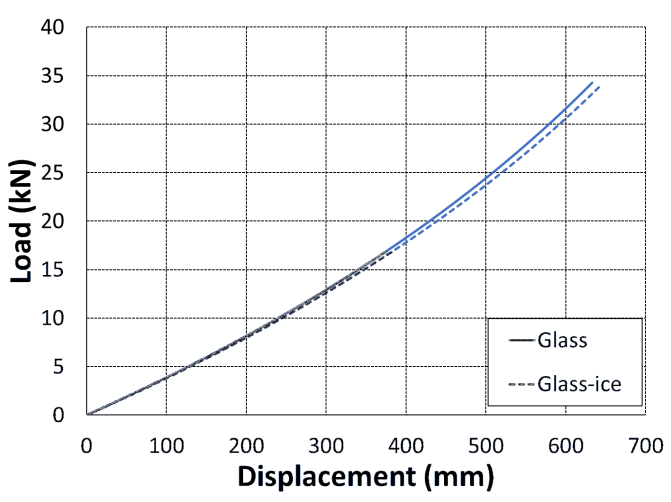

(b) Glass

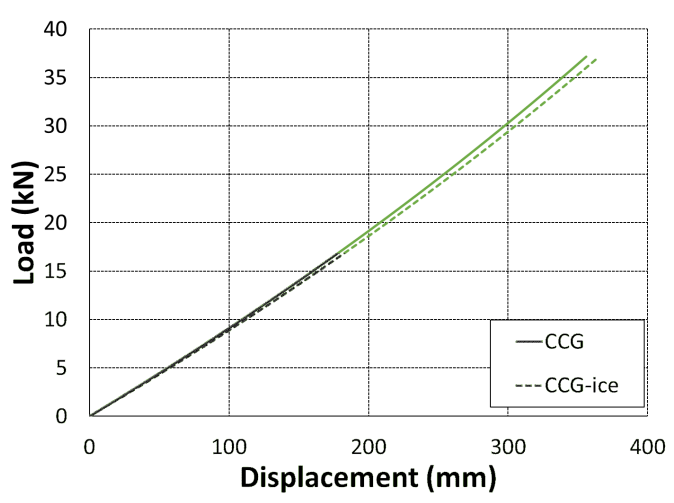

(c) CGG

Figure 5: Mechanical behavior of the clean and iced composite blade, for different materials

Figure 5 shows a comparison of load-displacement curves with various composite materials. It can be seen that the clean blade always moves less when the ice is formed at its extremity.Glass fibershave a maximum displacement value of about $632.808 \mathrm{~mm}$ for the clean blade and increases by about $2 \%$ for the 
iced one to reach a value of $645.492 \mathrm{~mm}$. While the Carbon fibers have the smallest maximum displacement and a maximum force value respectively $34.968 \mathrm{kN}$ and $34.900 \mathrm{kNfor}$ the clean and iced blade, which makes an approximate reduction of $0.195 \%$.

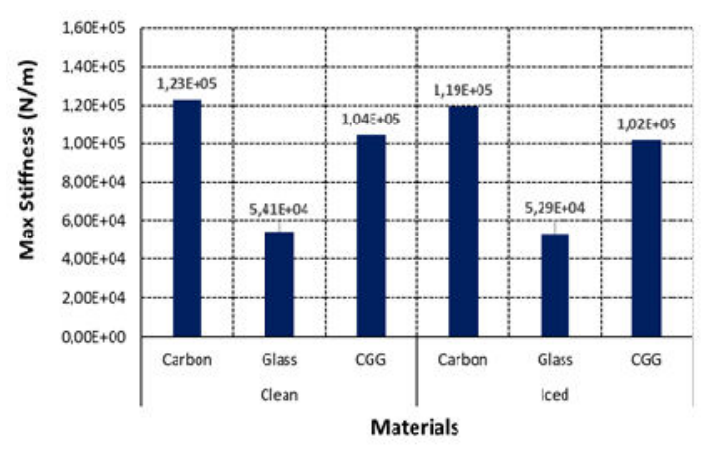

Figure 6: Maximum stiffness of the clean and iced composite blade

From Figure 6, it is clear that the maximum stiffness values vary according to the material. It is also distinguished that Carbon fibershave always the high stiffness value $\left(1.23010^{5} \mathrm{~N} / \mathrm{m}\right.$ for clean blade, and $1.19410^{5} \mathrm{~N} / \mathrm{mfor}$ iced blade)compared to other materials, which makes it the best choice for the blade design to keep it as light and as rigid as possible.

Table4: Hashin failure data of the clean and iced composite blade

\begin{tabular}{cccc} 
& \multicolumn{1}{c}{ Carbon } & Glass & CGG \\
\hline \multicolumn{4}{c}{ Clean } \\
\hline HSNFCCRT & $3,73 \mathrm{E}-03$ & $7,34 \mathrm{E}-03$ & $4,77 \mathrm{E}-03$ \\
\hline HSNFTCRT & $1,83 \mathrm{E}-02$ & $3,98 \mathrm{E}-02$ & $2,32 \mathrm{E}-02$ \\
\hline HSNMCCRT & $5,79 \mathrm{E}-02$ & $3,18 \mathrm{E}-01$ & $7,66 \mathrm{E}-02$ \\
\hline HSNMTCRT & $1,30 \mathrm{E}-01$ & $1,00 \mathrm{E}+00$ & $2,35 \mathrm{E}-01$ \\
\hline \multicolumn{4}{c}{ Iced } \\
\hline HSNFCCRT & $3.98 \mathrm{E}-03$ & $7.74 \mathrm{E}-03$ & $4.77 \mathrm{E}-03$ \\
\hline HSNFTCRT & $1.98 \mathrm{E}-02$ & $4.40 \mathrm{E}-02$ & $2.32 \mathrm{E}-02$ \\
\hline HSNMCCRT & $6.25 \mathrm{E}-02$ & $3.42 \mathrm{E}-01$ & $7.66 \mathrm{E}-02$ \\
\hline HSNMTCRT & $1.40 \mathrm{E}-01$ & $1,00 \mathrm{E}+00$ & $2.35 \mathrm{E}-01$ \\
\hline
\end{tabular}

Table 4 containsthe results of Hashinfailure criterion of the clean and iced composite blade. A value of 1.0 was obtained for the matrix tension (HSNMTCRT) of a Glass blade, indicating that the initiation criterion was achieved.

The damage occurred at the root of the composite blade of the wind turbine due to the thickness transitions, which is highlighted in Figure 17 by the red color.

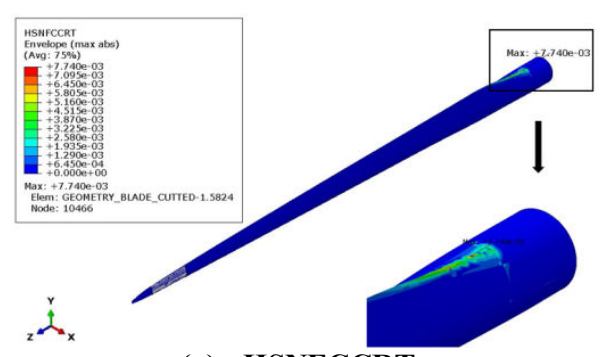

(a) HSNFCCRT

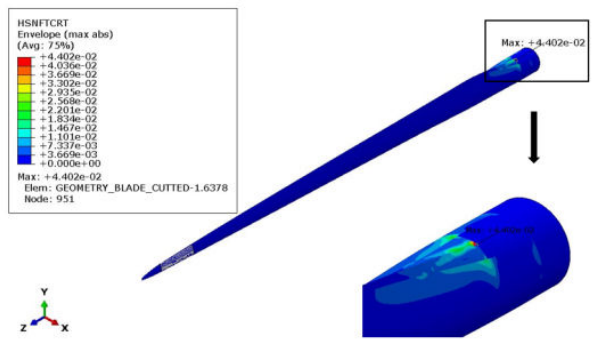

(b) HSNFTCRT

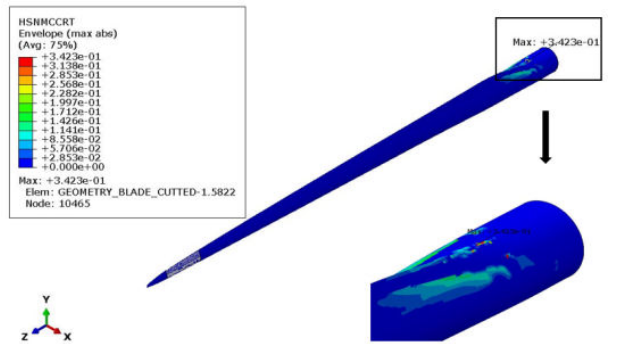

(c) HSNMCCRT

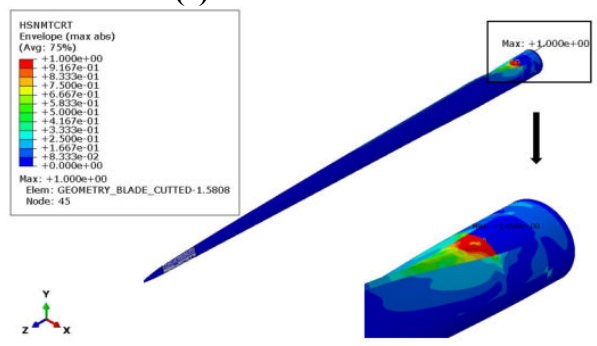

(d) HSNMTCRT

Figure 7: Hashindamage criterionforglass composite blade with $50 \mathrm{~mm}$ of ice

\section{CONCLUSIONS}

In this work, rotor performance analysis of a wind turbines placed on a horizontal position subject to icing event was performed using ABAQUS software. The blade in service was exposed to three loads at the same time with $50 \mathrm{~mm}$ of ice thickness located on its tip. Carbon, Glass fibers and hybrid Carbon-Glass (CGG) are the materials adopted for the conception of the blade structure. It was found that the Carbon is the strongest and most resistant 
material.The root of the composite blade of the wind turbine was defined as the most susceptible region to damage and breakage. It is therefore essential to reinforce this area in order to have a stronger structure.

\section{REFERENCES}

[1] Tarfaoui, M., rahaman shah, owaisur, \&Nachtane, M. 2019. Design and optimization of composite offshore wind turbine blades. Journal of Energy Resources Technology.

[2] Yirtici, O., \&Tuncer, I. H. 2020. Aerodynamic Shape Optimization of Wind Turbine Blades to Reduce Power Losses due to Icing.

[3]Wang, Q., Xiao, J., Zhang, T., Yang, J., \& Shi, Y. 2020. A new wind turbine icing computational model based on Free Wake Lifting Line Model and Finite Area Method.

[4]O’Leary, K., Pakrashi, V., \&Kelliher, D. 2019. Optimization of composite material tower for offshore wind turbine structures. Renewable Energy.

[5]M. Tarfaoui, J.Y. Pradillon, O.R. Shah. 2015. Numerical investigation of a large composite wind turbine with different spar profiles using finite-element method. La Houille Blanche, $\mathrm{n}^{\circ} 5$, $\mathrm{p}$. 29-35

[6]M.Nachtane, M.Tarfaoui, D.Saifaoui, A.El Moumen. Finite element analysis of composite wind turbine blade under the critical loads. Eleven International Conference on Thermal Engineering: Theory and Applications February 25-28, 2018, Doha, Qatar.

[7] R.Abouchoukri. 2018. Design, Fabrication, and Operation of a Small homemade Wind Turbine Blades.

[8] Tarfaoui, M., Nachtane, M., Khadimallah, H., \&Saifaoui, D. 2017. Simulation of Mechanical Behavior and Damage of a Large Composite Wind Turbine Blade under Critical Loads. Applied Composite Materials, 25(2), 237-254.

[9] M. Nachtane, M. Tarfaoui, M.Ait Mohammed, D. Saifaoui, A. El Moumen. Effects of environmental exposure on the mechanical properties of composite tidal current turbine. Renewable Energy 2020, 156, 1132-1145.

[10]Nachtane, M., Tarfaoui, M., Goda, I., \&Rouway, M. 2020. A review on the technologies, design considerations and numerical models of tidal current turbines. Renewable Energy.

[11] M.Nachtane, M.Tarfaoui, D.Saifaoui, A.El Moumen, O.H.Hassoon, H.Benyahia. 2018. Evaluation of durability of composite materials applied to renewable marine energy: Case of ducted tidal turbine. Energy Reports, Volume 4, Pages 31-40.

[12] Gemi, L. 2018. Investigation of the effect of stacking sequence on low velocity impact response and damage formation in hybrid composite pipes under internal pressure. A comparative study. Composites Part B: Engineering, 153, 217-232.

[13]Gu, J., \& Chen, P. 2017. Some modifications of Hashin's failure criteria for unidirectional composite materials. Composite Structures, 182, 143-152.

[14] K.Kodagali., 2017. Thesis, Progressive Failure Analysis of composite Materials using the Puck Failure Criteria.

[15] Kim Martineli Souza Gonçalves. 2015. Hashin's Failure Criteria In-Plane Stress Numerical Model Correlated to Tensile Tests. International Journal of Engineering Research and Science \& Technology.

[16] H. Boudounit, M. Tarfaoui, D. Saifaoui. 2019. Structural Design and Analysis of a 5MW Offshore Wind Turbine Blades Under Critical Aerodynamic Loads. 14th Congress of Mechanics April 16-19, 2019 (Rabat, MOROCCO).

[17]Söker, H. 2013. Loads on wind turbine blades. Advances in Wind Turbine Blade Design and Materials, 29-58. 